\title{
Bioclimatic zonation and potential distribution of Spodoptera frugiperda (Lepidoptera: Noctuidae) in South Kivu Province, DR Congo
}

Marcellin C. Cokola ${ }^{1,2^{*}}$ (D, Yannick Mugumaarhahama ${ }^{3,4}$, Grégoire Noël ${ }^{2}$, Espoir B. Bisimwa ${ }^{1,5}$, David M. Bugeme ${ }^{5}$, Géant B. Chuma ${ }^{1,4}$, Adrien B. Ndeko ${ }^{1}$ and Frédéric Francis ${ }^{2}$

\begin{abstract}
Background: The fall Armyworm (FAW) Spodoptera frugiperda (JE Smith), is currently a devastating pest throughout the world due to its dispersal capacity and voracious feeding behaviour on several crops. A MaxEnt species distributions model (SDM) was developed based on collected FAW occurrence and environmental data's. Bioclimatic zones were identified and the potential distribution of FAW in South Kivu, eastern DR Congo, was predicted.

Results: Mean annual temperature (bio1), annual rainfall (bio12), temperature seasonality (bio4) and longest dry season duration (IIds) mainly affected the FAW potential distribution. The average area under the curve value of the model was 0.827 demonstrating the model efficient accuracy. According to Jackknife test of variable importance, the annual rainfall was found to correspond to the highest gain when used in isolation. FAWs' suitable areas where this pest is likely to be present in South Kivu province are divided into two corridors. The Eastern corridor covering the Eastern areas of Kalehe, Kabare, Walungu, Uvira and Fizi territories and the Western corridor covering the Western areas of Kalehe, Kabare, Walungu and Mwenga.
\end{abstract}

Conclusions: This research provides important information on the distribution of FAW and bioclimatic zones in South Kivu. Given the rapid spread of the insect and the climatic variability observed in the region that favor its development and dispersal, it would be planned in the future to develop a monitoring system and effective management strategies to limit it spread and crop damage.

Keywords: Bioclimatic zone, Potential distribution, Spodoptera frugiperda, MaxEnt model, Environmental variables

\section{Background}

The Fall Armyworm (FAW) Spodoptera frugiperda (J.E Smith 1797) is native to tropical and subtropical Americas $[14,20]$ and a major corn pest [30]. Its presence was first reported on the African continent in 2016 [20] and

\footnotetext{
*Correspondence: marcellin92cokolacuma@gmail.com

${ }^{1}$ Unit of Crop Sciences, Faculty of Agriculture and Environmental

Sciences, Université Evangélique en Afrique, South Kivu, P.O Box: 3323,

Bukavu, Democratic Republic of Congo

Full list of author information is available at the end of the article
}

in Asia later on in 2018 [51, 52]. Whether FAW larvae is able to infest more than 80 crop species $[18,46]$, main damages were observed on grasses family (Poaceae) including corn, rice and sorghum [34]. Yield losses can reach up to $73 \%$ when $100 \%$ of the plants are infested with FAW [27]. According to Baudron et al. [5], maize infestation of $54.9 \%$ might have an impact on yield of approximately $12 \%$. Due to its polyphagous feeding behavior and recent introduction in the African continent, FAW is expected to constitute a lasting threat to several important crops in African [20]. Studies on

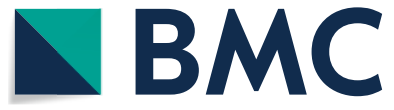

(c) The Author(s) 2020. This article is licensed under a Creative Commons Attribution 4.0 International License, which permits use, sharing, adaptation, distribution and reproduction in any medium or format, as long as you give appropriate credit to the original author(s) and the source, provide a link to the Creative Commons licence, and indicate if changes were made. The images or other third party material in this article are included in the article's Creative Commons licence, unless indicated otherwise in a credit line to the material. If material is not included in the article's Creative Commons licence and your intended use is not permitted by statutory regulation or exceeds the permitted use, you will need to obtain permission directly from the copyright holder. To view a copy of this licence, visit http://creativeco mmons.org/licenses/by/4.0/. The Creative Commons Public Domain Dedication waiver (http://creativecommons.org/publicdomain/ zero/1.0/) applies to the data made available in this article, unless otherwise stated in a credit line to the data. 
the behavioral characteristics of FAW strains in the Western Hemisphere indicated that two main strains, namely on rice and on maize, are able to mate with each other despite the existence of hybridization barriers [35, 38, 47, 50]. Both rice and maize strains can be found and collected from a single host plant species [29, 37, 47]. Given these characteristics, Nagoshi et al. [36] have even reported that the African infestation may represent a new hybrid population with potentially uncertain behavioral feeding characteristics to become a serious problem for Africa, including Democratic Republic of Congo (DRC).

The fall armyworm has only invaded areas that have a climate pattern similar to the native distribution, justifying the use of climatic Species Distribution Models (SDMs) for further predictive spreading [14]. In recent years, an increasing number of tools for spatial analysis of species distribution at different spatial scales have emerged [21, 28]. These tools have become increasingly popular in ecology. Particularly, niche distribution models were widely used in many ecological applications [41]. In fact, several methods of SDMs, also known as ecological niche modeling (ENM) have been developed [19]. In order to estimate the functional response related to various environmental variables [2], SDMs relate known locations of a species with their environmental characteristics, and then predict the potential geographical range of that species [17]. According to Westbrook et al. [56], the initiation and displacement patterns of insect migrations are dependent on these environmental factors.

Distribution of FAW has been investigated by Wang et al. [55] and Liu et al. [32] using SDM MaxEnt (Maximum Entropy). Also, the FAW distribution was modeled on a large scale using CLIMEX software integrating the species model "Wet tropical" [13]. Using similar software and two general circulation models (GCMs), RamirezCabral et al. [49] assessed the climate change impact on future suitability for FAW expansion. Furthermore, Early et al. [14] used Species distribution models (SDMs) to forecast FAW global extent. However, FAW occurrence in South Kivu (Eastern DR Congo) has been reported by Cokola [10] but its distribution remains unknown. Several areas in South Kivu are favourable to FAW development according to suitable temperature, day length and precipitation during warm/wet season as provided by Abraham et al. [1].

Modeling potential distribution of species in relation to climatic conditions is an important tool to apply such as in South Kivu where FAW geographical distribution is still unknown. A FAW modeled proposal will be useful for further FAW monitoring and management in case of high scale infestations. Therefore, this study aims to determine bioclimatic zones and establish potential distribution of FAW in South Kivu, eastern Democratic Republic of Congo (DRC).

\section{Results \\ Bioclimatic zones of the South Kivu province}

Three bioclimatic zones obtained by clustering using bioclimatic data were presented (Fig. 1). The respective characteristics (mean \pm standard error) of each zone are given in Table 1 . Zone 1 is mainly characterized by very high mean daytime temperature range and rainfall parameters (seasonality, duration for the wettest period, in the wettest quarter and annual values). Furthermore, it has very low temperature means (annual, for warmest and coldest quarters, for hottest month and potential evapotranspiration). Also, zone 2 is characterized by very high isothermal and specific rainfall conditions (during driest period, annually, for wettest quarter and moisture index for dry quarter). In addition, it is characterized by very short duration of dry season, very low temperature seasonality and annually, annual moisture index, mean daytime temperature range. Finally, zone 3 was characterized by very high annual temperature and for warmest quarter, longest dry season, very high annual moisture index. However, it was also characterized by very low annual rainfall and for wettest quarter, isothermality and moisture index of the dry quarter. Zones 1, 2 and 3 represented high, low and medium altitude areas respectively.

\section{Model performance}

In this study, from the ROC curves, AUC values were used to evaluate the performance of the MaxEnt model. Many studies showed that an AUC of high values leads to better results that significantly differed from the random predictions. The next picture is the receiver operating characteristic (ROC) curve showing the performance of the FAW MaxEnt model. The prediction accuracy of FAW MaxEnt model was found to be acceptable (AUC mean of $0.827 \pm 0.033$, Fig. 2) according to the identified evaluation criteria.

The suitable areas of FAW in South Kivu province are divided into two corridors (Fig. 3): one covering eastern Kalehe, Kabare, Walungu, Uvira and Fizi territories and another the western areas of Kalehe, Kabare, Walungu and Mwenga territories, southern Shabunda and northwestern Fizi territories. The most suitable areas for FAW in South Kivu are mostly located in bioclimatic zone 3. In bioclimatic zones 1 and 2, the probabilities of FAW occurrence are very low (medians below 0.063). As for bioclimatic zone 3 , the probabilities of occurrence are relatively higher, with a median of 0.29 . In South Kivu, FAW are most likely to be found in areas characterized by very high annual temperature range, longest dry season, very high annual moisture index. Furthermore, these 


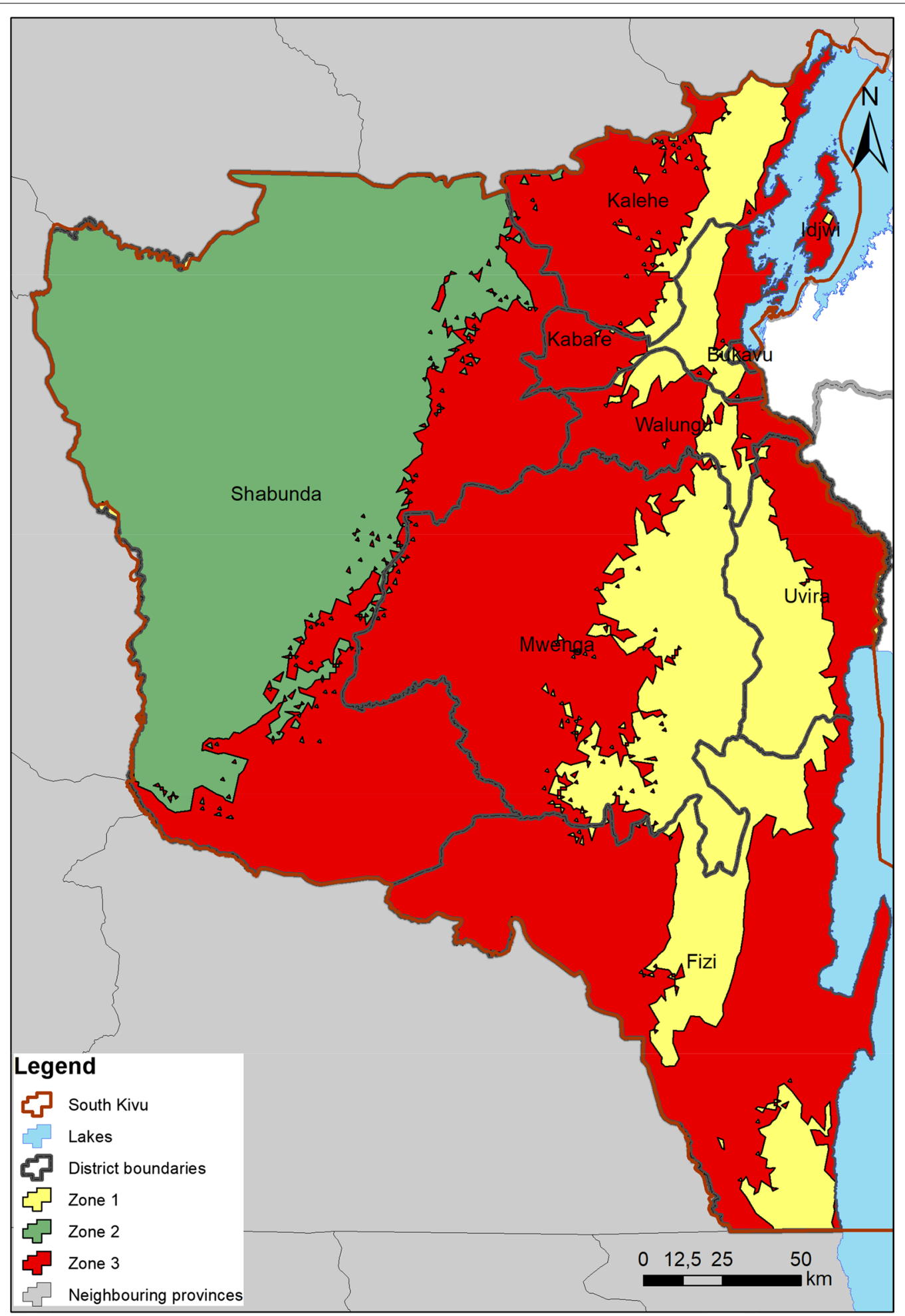

Fig. 1 Bioclimatic zones of South Kivu. The zones are indicated in different colors on the map. This figure was created by the authors using ArcMap version 10.6 (https://desktop.arcgis.com/fr/arcmap/) 
Table 1 Description of bioclimatic zones of South Kivu (Mean \pm SE)

\begin{tabular}{|c|c|c|c|c|}
\hline Variables & Zone 1 & Zone 2 & Zone 3 & Global \\
\hline bio1 & $160.82 \pm 19.96$ & $227.28 \pm 16.12$ & $220.09 \pm 18.06$ & $210.53 \pm 30.83$ \\
\hline bio2 & $95.55 \pm 4.53$ & $106.89 \pm 2.10$ & $105.46 \pm 4.75$ & $103.93 \pm 5.85$ \\
\hline bio3 & $792.26 \pm 39.18$ & $857.40 \pm 17.18$ & $790.86 \pm 35.53$ & $812.91 \pm 44.31$ \\
\hline bio4 & $3.931 \pm 0.80$ & $2.99 \pm 0.09$ & $3.63 \pm 0.80$ & $3.48 \pm 0.75$ \\
\hline bio5 & $219.70 \pm 23.05$ & $288.97 \pm 16.19$ & $285.48 \pm 18.98$ & $273.40 \pm 33.02$ \\
\hline bio6 & $98.69 \pm 16.75$ & $164.26 \pm 16.41$ & $152.09 \pm 17.09$ & $145.34 \pm 29.30$ \\
\hline bio7 & $121.00 \pm 9.754$ & $124.70 \pm 4.00$ & $133.39 \pm 4.15$ & $128.06 \pm 7.72$ \\
\hline bio10 & $164.05 \pm 20.37$ & $229.63 \pm 16.14$ & $224.03 \pm 18.06$ & $213.81 \pm 30.84$ \\
\hline bio11 & $155.27 \pm 20.02$ & $223.59 \pm 16.35$ & $215.82 \pm 18.31$ & $206.19 \pm 31.47$ \\
\hline bio12 & $1893.89 \pm 149.49$ & $1940.80 \pm 147.15$ & $1563.16 \pm 167.94$ & $1753.17 \pm 239.61$ \\
\hline bio13 & $248.36 \pm 27.76$ & $235.78 \pm 24.11$ & $198.67 \pm 16.41$ & $220.80 \pm 30.48$ \\
\hline bio14 & $17.38 \pm 8.03$ & $55.42 \pm 13.17$ & $21.59 \pm 10.16$ & $31.81 \pm 19.79$ \\
\hline bio15 & $80.28 \pm 11.02$ & $61.72 \pm 6.24$ & $63.03 \pm 6.53$ & $66.07 \pm 10.41$ \\
\hline bio16 & $668.48 \pm 65.06$ & $668.73 \pm 62.81$ & $549.53 \pm 50.97$ & $612.44 \pm 83.07$ \\
\hline bio17 & $89.43 \pm 35.89$ & $198.67 \pm 34.19$ & $93.86 \pm 38.22$ & $127.25 \pm 61.75$ \\
\hline Dem & $2197.31 \pm 348.68$ & $847.65 \pm 283.62$ & $1145.35 \pm 326.32$ & $1259.45 \pm 582.61$ \\
\hline Llds & $2.69 \pm 0.81$ & $1.26 \pm 1.13$ & $3.29 \pm 0.59$ & $2.51 \pm 1.23$ \\
\hline $\mathrm{Mi}$ & $147.95 \pm 23.30$ & $118.39 \pm 8.86$ & $98.43 \pm 12.58$ & $114.91 \pm 23.68$ \\
\hline Miaq & $29.30 \pm 13.16$ & $50.70 \pm 8.95$ & $24.02 \pm 9.79$ & $33.81 \pm 15.77$ \\
\hline Mimq & $212.43 \pm 35.75$ & $160.83 \pm 13.39$ & $140.35 \pm 15.53$ & $161.54 \pm 34.09$ \\
\hline Pet & $1295.55 \pm 100.38$ & $1640.62 \pm 65.71$ & $1595.30 \pm 92.60$ & $1549.86 \pm 155.42$ \\
\hline Total area $\left(\mathrm{km}^{2}\right)$ & $11,411.20$ & $17,293.40$ & $30,389.80$ & $59,094.40$ \\
\hline
\end{tabular}

SE standard error

zones are also characterized by very low rainfall (annually, in the wettest quarter, during the wettest month).

\section{Analysis of variable contributions}

The estimates of relative contributions of the environmental variables to the FAW MaxEnt model are presented (Figs. 4, 5) showing that bio12 (Annual rainfall) played a major role in the FAW spread. Furthermore, the environmental variable with highest gain when used in isolation was bio12 (Annual rainfall) according to the Jackknife test of variable importance (Fig. 5). This environmental variable also decreases the most the gain while omitted, but also having the most useful information by itself and much more that is not available in the other variables. The bio12 variable was highly correlated with bio7 (Annual temperature range), bio13 (Rainfall of wettest month), bio16 (Rainfall of wettest quarter) and mi (Annual moisture index). Thus, it appears that these four variables also play a major role in the speed of FAW in South Kivu.

\section{Response of variables to suitability}

The mean responses of variables to FAW habitat suitability over 100 replicate MaxEnt runs (red) and the mean \pm one standard deviation (blue, two shades for categorical variables) are presented. The bio12 (annual rainfall with less than $1600 \mathrm{~mm}$ ) variable plays a major role in the FAW distribution according to the Jackknife test (Fig. 5). Furthermore, with a strong negative correlation with bio7 (annual temperature range), FAW also favours locations with high annual temperature. The probability of FAW occurrence is high in environments where (1) mean annual temperature (bio1) is comprised between $19{ }^{\circ} \mathrm{C}$ and $23{ }^{\circ} \mathrm{C}$; (2) temperature seasonality (bio4) is less than 2.5 and (3) length of the longest dry season (llds) comprised between 2.5 and 4.5 (Fig. 6).

\section{Discussion}

The FAW is a tropical species mostly adapted to warmer parts of the New World [9]. In the current study, we modeled its distribution under tropical conditions in Eastern DR Congo. The existence of 3 bioclimatic zones for FAW was determined in South Kivu. One (zone 3) was found to correspond to the highest probability of FAW occurrence. Climate change has been reported to have different effects on insects, impacting directly their life cycles or indirectly their hosts and/or predators [3, 39]. However, the FAW may benefit from the climate change due to its polyphagous feeding behaviour, its phenotypic and genotypic plasticity [49]. Also, the adult 


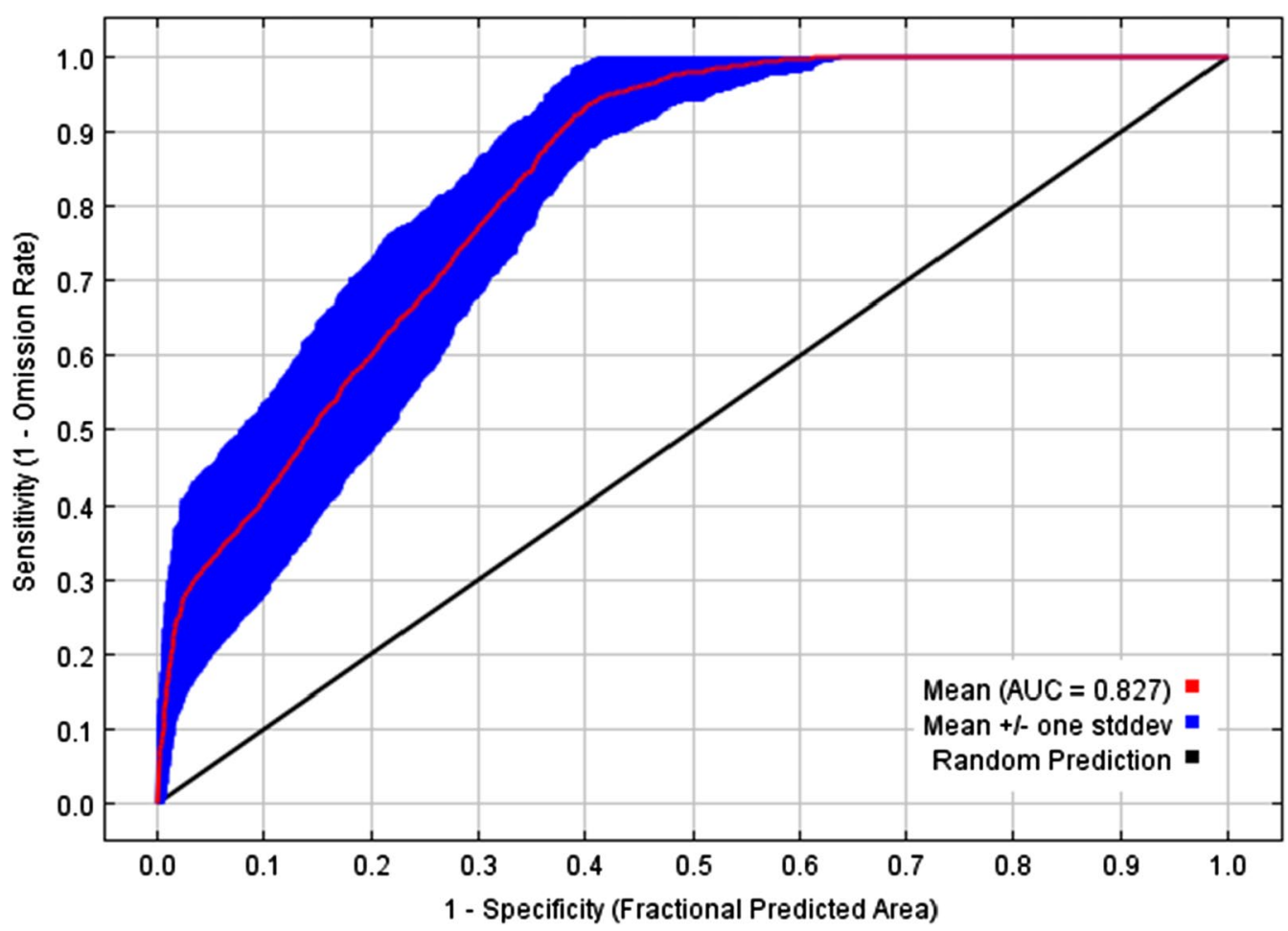

Fig. 2 Receiver Operating Characteristic (ROC) curve and Area Under the Curve (AUC) value of MaxEnt modeling (100 runs)

migratory ability is one more adaptative trait to allow moving across regions to several miles (300 miles/generation in some years) $[54,57]$. In an area such as South Kivu with an approximate surface area of $69,130 \mathrm{~km}^{2}$, the FAW migration would take place very quickly. Outbreaks of FAW are closely related to climate conditions and with good winter and spring conditions [49]. Cokola [10] noted that FAW incidence in South Kivu has been associated by temperature and rainfall. Moreover, study conducted by Liu et al. [32] founded that land-use was more important than climate factors, with larger potential distributions. In this study, among the 21 used bioclimatic variables, four of them influenced the potential distribution of FAW in the region. It is therefore seen that these four variables also play a major role in the spread of FAW in South Kivu. Wang et al. [55] modelled the distribution of FAW through MaxEnt with 19 bioclimatic variables related to temperature and humidity of which 10 influenced the FAW distribution. However, the FAW distribution may be influenced by other several non-climatic factors, such as host, natural enemy, management level and human activities [24], soil properties, land cover and agricultural management interventions (such as use of pesticides or fertilizers) [6]. This aspect need to be then incorporated into the model. Furthermore, it would also be important to model the FAW distribution by integrating local bioclimatic data into the model to minimize errors related to imported bioclimatic data. Soria-Auza et al. [53] reported that one of the least studied sources of uncertainty in species distribution modeling comes from the environmental data used to run the models, particularly the climate data, especially in the tropics, where comparatively few climatic stations are available. In the case of South Kivu province, however, it is difficult to obtain sufficient local bioclimatic data given the limited number of meteorological stations found in this region.

The accuracy of prediction of FAW MaxEnt model showed high values of AUC (Fig. 2) confirming a good model performance [33]. Comparing our results with other studies, including Wang et al. [55], an excellent AUC was found. For instance, AUC often increases with the size of the study area because it contributes to include background points that have environmental characteristics greatly distant from the species requirement, resulting in artificial increase of SDM validation [4]. The suitable areas of FAW in South Kivu province are divided into two corridors (Fig. 3). The Eastern corridor covering the Eastern areas of Kalehe, Kabare, Walungu, Uvira and Fizi territories and the Western corridor covering the Western areas of Kalehe, Kabare, Walungu and Mwenga territories, southern Shabunda and north-western Fizi territories. Infestations are most prevalent in the first corridor. Differences in the FAW infestations within the said corridor, between the Ruzizi plain (low altitude) 


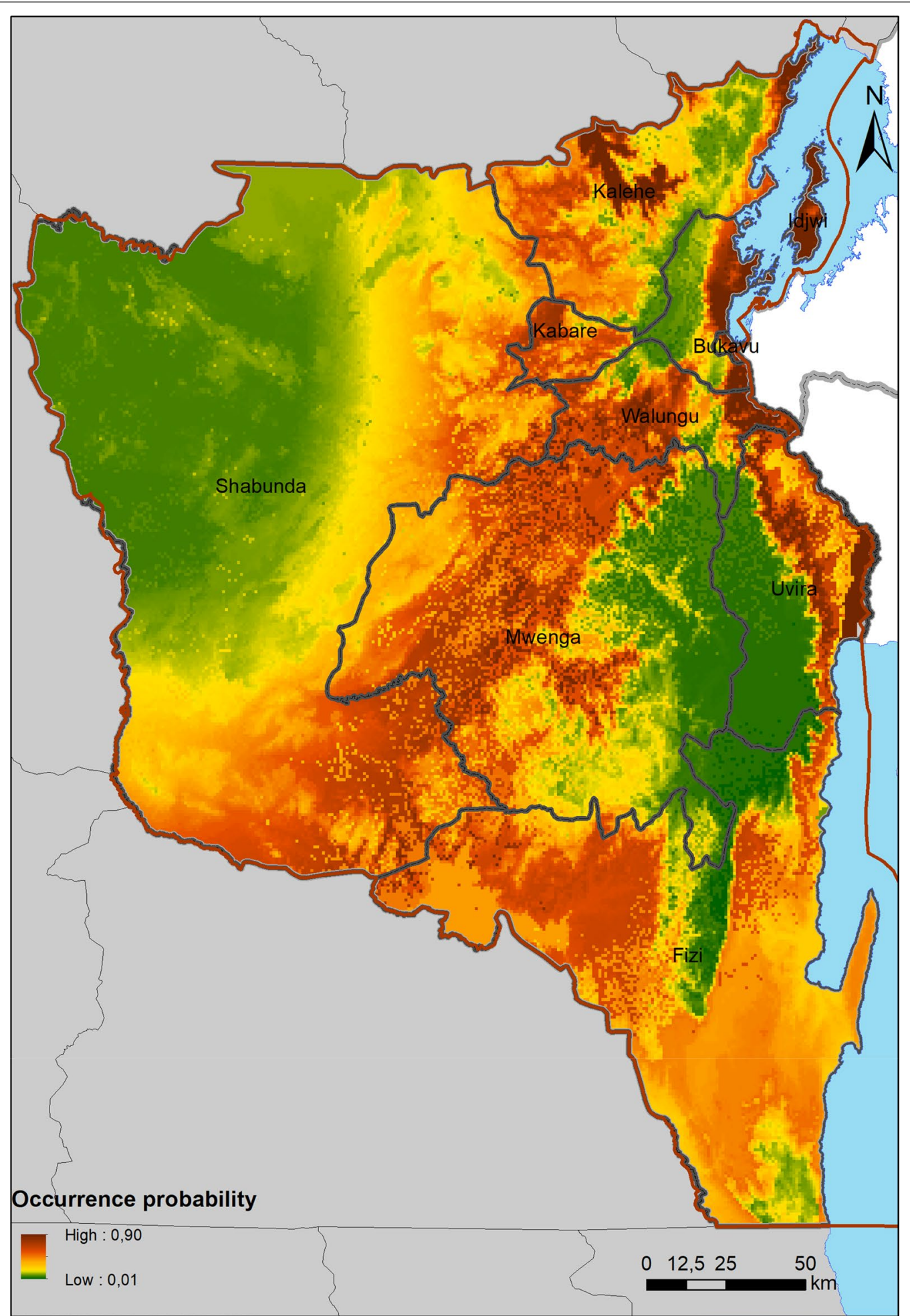

Fig. 3 Distribution of suitable areas of fall armyworm (Spodoptera frugiperda) in South Kivu, DRC. This figure was created by the authors using ArcMap version 10.6 (https://desktop.arcgis.com/fr/arcmap/) 

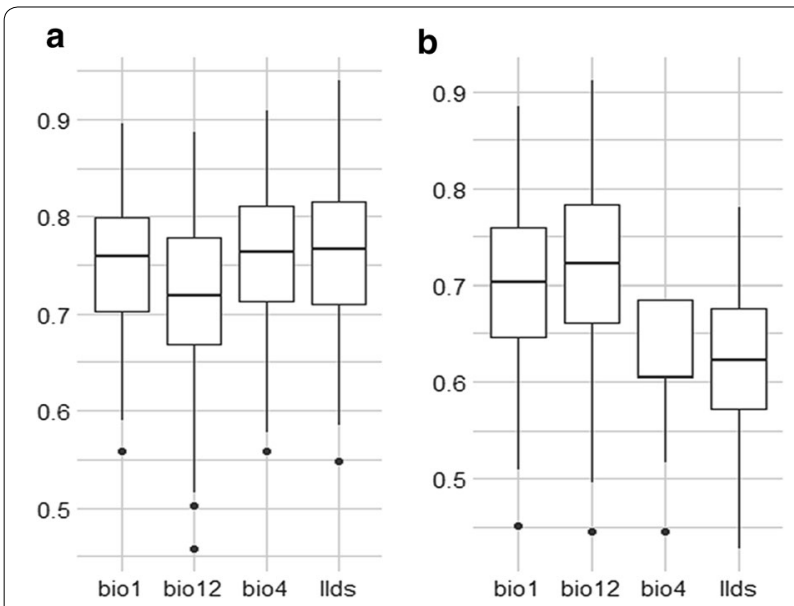

Fig. 4 Contribution (a) and Permutation importance (b) of variables used as predictors in the fall armyworm (Spodoptera frugiperda)

MaxEnt model. bio1: mean annual temperature; bio12: annual rainfall; bio4: temperature seasonality; llds: longest dry season duration

and Kabare (mid altitude) have been demonstrated [10]. According to the modeling realized by Early et al. [14], Sub-Saharan Africa, especially DR Congo, Gabon and Cameroon, appeared to have low suitability for FAW. Early et al. [14] explain that low suitability in these countries was more likely because of extensive forest cover. This is the case for example, here for Shabunda territory. However, this does not mean that pockets of the suitable habitats in the cited countries will not be severely affected, given the ability of the FAW to travel long distances [14].

Among the four environmental variables used as predictors in the FAW MaxEnt model, bio12 (annual rainfall) played a major role in the spread of FAW and contributed more to run the MaxEnt model (Fig. 5). With the Jackknife test for variable importance, the environmental variable exhibited highest gain when used in isolation with bio12 (annual rainfall). Day et al. [12] found that rainfall in the wettest periods and the coldest annual temperatures were important variables in FAW migration. The effects of rainfall on the distribution of FAW have been documented. For example, Early et al. [14] reported that rainfall have a negative impact on FAW larvae. Furthermore, a suitability map provided by Du Plessis et al. [13] demonstrated that natural rainfall and irrigation scenario were important variables in FAW distribution. The coldest annual temperature and the rainfall during the wettest three months were consistently identified by Early et al. [14] as the environmental variables that most affected FAW distribution. In this work, most suitable habitat for FAW was found in places where annual rainfall was less than $1600 \mathrm{~mm}$. According to Early et al. [14] and Nagoshi et al. [15], FAW was most commonly found in areas with very little forest cover, a minimum annual temperature of $18-26^{\circ} \mathrm{C}$ and with $500-700 \mathrm{~mm}$ rainfall in the three wettest months. Furthermore, given that variable bio12 is strongly negatively correlated with bio7 (annual temperature range), it seems clear that FAW also favours locations with high annual temperature. Temperature was the main environmental factor affecting the growth and reproduction of the FAW $[8,25]$. FAW was most likely to be found in areas characterized by very high annual temperature range, very long duration of the longest dry season, very high annual moisture index, high maximum temperature of the hottest month and very high mean temperature of the warmest quarter. The probability of FAW occurrence is high in environments where mean annual temperature (bio1) is comprised between $19{ }^{\circ} \mathrm{C}$ and $23{ }^{\circ} \mathrm{C}$. Du Plessis et al. [22] found that the development rate of FAW increased linearly with increasing temperatures between 18 and $30{ }^{\circ} \mathrm{C}$. Additionally, Wang et al. [55] found that when the Mean Temperature of the Warmest Quarter varies between 19.15 and $29.73{ }^{\circ} \mathrm{C}$, the existence probability of the FAW is higher.

\section{Conclusion}

In areas where investigations on FAW invasions remain limited, such as in the DR Congo, it is important to model its distribution and to detect areas with high infestation potential. Based on the obtained results, the South Kivu province is a favorable habitat for the development of FAW. However, given the rapid spread of the insect and the climatic variability observed in the region that favor its development and dispersal, it is necessary to pay particular attention to the management of this species now, in order to take effective measures and prevent its further spread. At the same time, effective and efficient monitoring systems should be set up in its range to collect field data's and improve further control of this pest.

\section{Methods}

\section{Study area and occurrence data collection}

This study focused on South Kivu in Eastern DR Congo, between $1^{\circ} 36^{\prime}$ and $5^{\circ}$ South Latitude; $26^{\circ} 47^{\prime}$ and $29^{\circ} 20^{\prime}$ East Longitude. Biological data's related to FAW occurrence were associated to locations with geo-referenced coordinates. Occurrence data of FAW were collected in Kalehe, Kabare, Walungu, Uvira, Fizi, Mwenga and Idjwi territories in collaboration with local farmers who observed FAW larvae and reported every related field in their localities. All suspected cases of FAW attacks were checked for confirmation through field surveys. To confirm that the larvae observed were indeed those of FAW, we had considered the morphological characteristics of FAW larvae as described by EPPO [16] and Sharanabasappa et al. [26]. Geographic coordinates of infested 


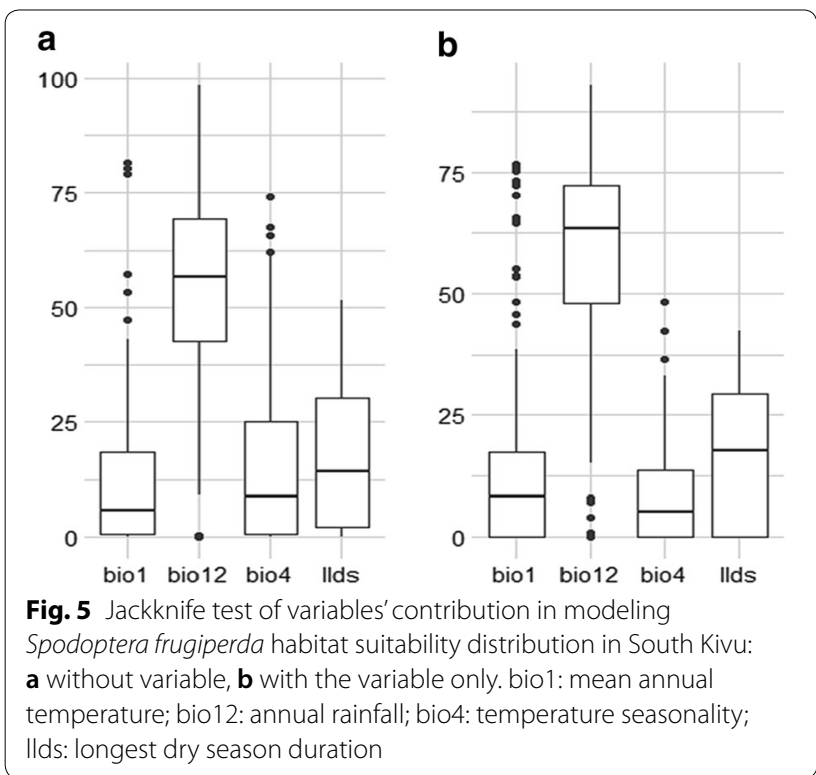

areas were selected only after positive FAW confirmation. Presence records were collected between February 2018 and September 2019 in 156 fields where FAW has been reported. Geographic coordinates on latitude and longitude in the WGS84 system were recorded using GPS Garmin $64 \mathrm{~s}$. The map representing the points of occurrence is illustrated in Fig. 7.

\section{Environmental variables}

In this study, we used elevation and potential evapotranspiration data's combined with 19 bioclimatic variables. Altitude (Digital Elevation Model ASTERDEM) with $30 \mathrm{~m}$ spatial resolution was obtained from USGS database (https://earthexplorer.usgs.gov) and the bioclimatic data's were collected from the Africlim database (https://www.york.ac.uk/environment/research/kite/ resources/). They were used to build the species distribution model in order to find the FAW suitable areas. Africlim provides high-resolution climate data's for Africa. Bioclimatic data consisted of 21 environmental variables (Table 2) that were obtained from interpolations of monthly averages of precipitation and temperature taking into account climate data collected over long periods of time (1950-2000) [23]. The Africlim spatial database includes monthly grids of temperature and rainfall, deriving from bioclimatic summary variables such as moisture indices and dry season length. All environmental variables were in raster format with a 30 arc seconds resolution $\left(0.93 \mathrm{~km} \times 0.93 \mathrm{~km} \approx 0.86 \mathrm{~km}^{2}\right.$ at the equator). Both ArcGIS Desktop 10.6 and QGIS 3.10 were used to process the spatial data: data extraction to the South Kivu province extent, data management in geographic coordinates (datum: WGS84) and resampling all the raster layers to the same resolution for preparing the maps.

\section{Bioclimatic zonation}

Initially, all the environmental variables $(n=21)$ were clipped to have only spatial data corresponding to the extent of the South Kivu province. Then, geographic coordinates of the raster pixels centroids were used to extract the values for each variables corresponding to each pixel in order to produce a dataset to be used to delineate the bioclimatic zones. The generated bioclimatic dataset was used by processing the Principal Component Analysis (PCA) procedure of the FactoMineR [31] package of the $\mathrm{R}$ software version 3.5.3 [48]. Based on Kaiser's criterion, only the first 5 principal components were selected for further analysis. The loadings of pixels centroids on the first 5 principal components were then used to perform a hierarchical ascending clustering through the HCPC (Hierarchical Clustering on Principle Components) procedure of the FactoMineR package. Hierarchical clustering was realised using the Euclidean distance as the metric and Ward's aggregation method to determine the optimal number of clusters to be formed. The Kmeans procedure was then used to consolidate the obtained clusters. Clustering results were then imported into QGis 3.10 to produce a bioclimatic zone map of the South Kivu province.

\section{Selection of environmental predictors}

Prior to distribution modeling, all the environmental variables were subjected to a correlation test in order to select those susceptible to be used as predictors of the FAW distribution. Consequently, only variables with pairwise Pearson correlation coefficients falling under the interval of ]-0.75, 0.75 [ were selected for modeling in order to control for multicolinearity problem in environmental predicators [58].

\section{Species distribution modeling}

MaxEnt (Maximum Entropy) program 3.3.3 [43, 44] was used to establish current climate envelope for FAW natural occurrence in South Kivu. MaxEnt is a common species distribution modeling (SDM) tool used for predicting the distribution of a species from a set of records and environmental predictors [19]. The MaxEnt technique uses known occurrence locations (presence only data) and a set of gridded environmental layers to produce an output map of the predicted ecological niche of the species on a scale of 0 (lowest suitability) to 1 (highest suitability). MaxEnt is a modeling technique that 

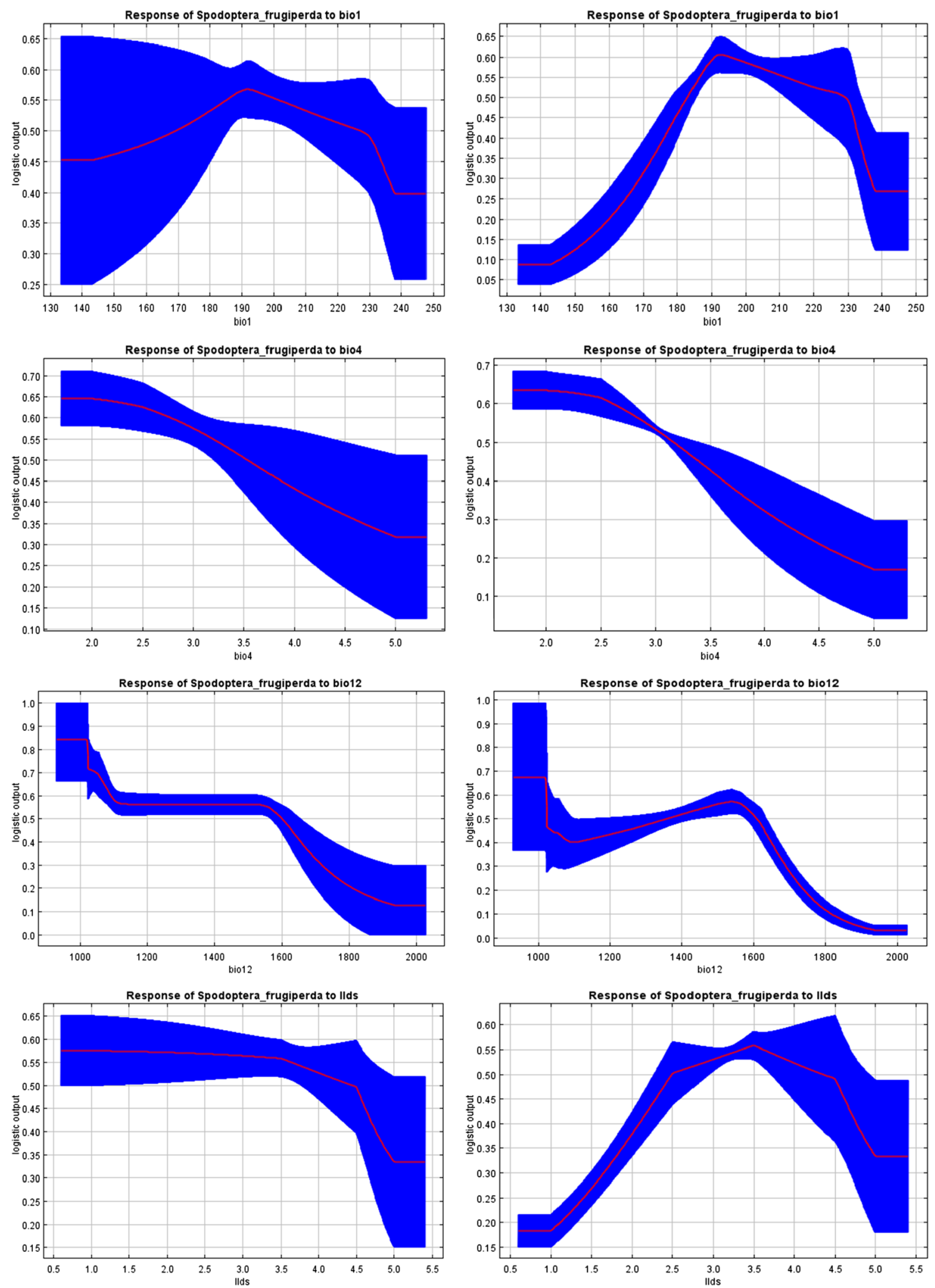

Fig. 6 Responses of variables to fall armyworm (Spodoptera frugiperda) habitat suitability. These curves show how each environmental variable affects the MaxEnt prediction. They also show how the predicted probability of presence changes as each environmental variable is varied, keeping all other environmental variables at their average sample value (left side) or a MaxEnt model created using only the corresponding variable (right side) 


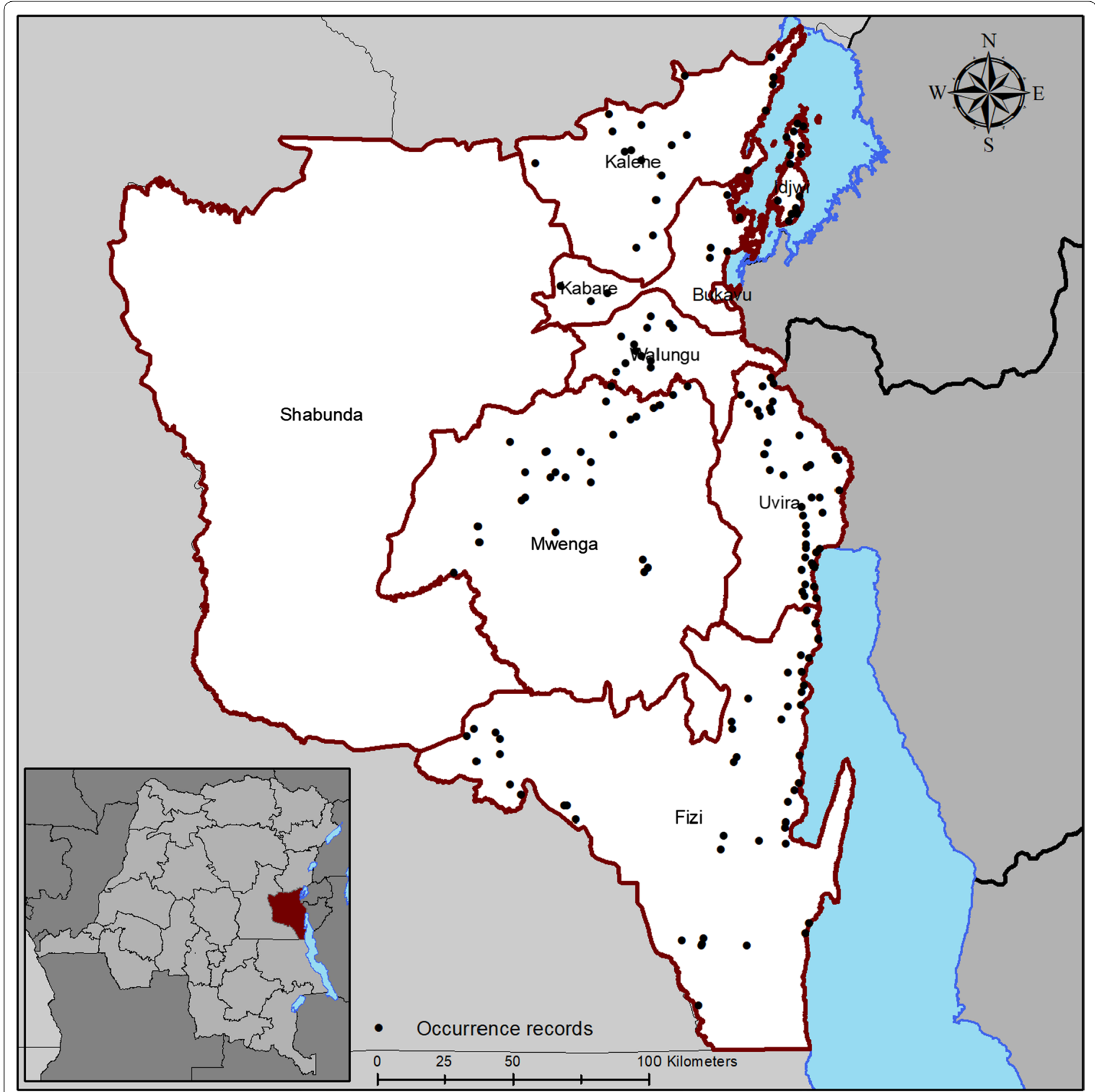

Fig. 7 Occurrence records of fall armyworm (Spodoptera frugiperda) in South Kivu, DRC. Each point represents a maize field in which fall armyworm larvae were detected and collected. This figure was created by the authors using ArcMap version 10.6 (https://desktop.arcgis.com/fr/arcmap/)

measures entropy, a measure of 'how much choice' is involved in the selection of an event [44, 45]. MaxEnt is a general-purpose method for characterizing probability distributions from incomplete information. In estimating the probability distribution defining a species distribution across a study area, MaxEnt formalizes the principle that the estimated distribution must agree with everything that is known (or inferred from the environmental conditions where the species has been observed) but should avoid making any assumptions that are not supported by the data [44]. The approach corresponded to find the probability distribution of maximum entropy (a distribution that is most spread-out, or closest to uniform) subject to constraints imposed by the information available regarding the species observed distribution and related environmental conditions across the study area 
Table 2 Environmental variables used to model Spodoptera frugiperda (FAW) distribution in South Kivu

\begin{tabular}{|c|c|c|}
\hline Environmental and bioclimatic parameters & Code & Units \\
\hline Mean annual temperature $(* 10)$ & bio1 & ${ }^{\circ} \mathrm{C}$ \\
\hline Mean daytime temperature range (monthly average) $(* 10)$ & bio2 & ${ }^{\circ} \mathrm{C}$ \\
\hline Isothermality (bio1/bio7) * 100 & bio3 & - \\
\hline Temperature seasonality (standard deviation * 100) & bio4 & ${ }^{\circ} \mathrm{C}$ \\
\hline Maximum temperature of the hottest month $(* 10)$ & bio5 & ${ }^{\circ} \mathrm{C}$ \\
\hline Minimum temperature of the coolest month $(* 10)$ & bio6 & ${ }^{\circ} \mathrm{C}$ \\
\hline Annual temperature range (bio5-bio6) $(* 10)$ & bio7 & ${ }^{\circ} \mathrm{C}$ \\
\hline Mean temperature of the warmest quarter $(* 10)$ & bio10 & ${ }^{\circ} \mathrm{C}$ \\
\hline Mean temperature of the coldest quarter $(* 10)$ & bio11 & ${ }^{\circ} \mathrm{C}$ \\
\hline Annual rainfall & bio12 & $\mathrm{mm}$ \\
\hline Rainfall during the wettest month & bio13 & $\mathrm{mm}$ \\
\hline Rainfall during the driest month & bio14 & $\mathrm{mm}$ \\
\hline Rainfall seasonality & bio15 & $\mathrm{mm}$ \\
\hline Rainfall in the wettest quarter & bio16 & $\mathrm{mm}$ \\
\hline Rainfall in the driest quarter & bio17 & $\mathrm{mm}$ \\
\hline Longest dry season duration & Ilds & - \\
\hline Annual moisture index & mi & - \\
\hline Moisture index of the dry quarter & miaq & - \\
\hline Moisture index of the wet quarter & mimq & - \\
\hline Potential evapotranspiration & pet & $\mathrm{mm}$ \\
\hline Elevation & dem & M \\
\hline
\end{tabular}

[44]. MaxEnt was presented as one of the highest performing SDM methods [7].

We ran 100 models, each trained to a randomly selected bootstrap process of the occurrence dataset. Prediction map from each model has been generated in order to calculate the mean prediction and standard deviation of each pixel. Model predictions were imported into ArcGis 10.6 to generate maps of the FAW occurrence probability in South Kivu.

\section{Model evaluation}

In this study, the Receiver Operating Characteristic (ROC) curve method was used to assess the model's performance [11, 40,42]. One of the parameters used to evaluate predictive capacity of a model generated by MaxEnt is the area under the curve (AUC) or under the ROC curve. AUC can then be interpreted as the likelihood that a randomly selected point of presence is located in a raster cell with a higher probability of species occurrence than a randomly generated point [44]. The AUC is an effective threshold-independent index that can evaluate a model's ability to discriminate presence from absence (or background) occurrence. Also, the AUC is not affected by collinearity and spatiotemporal autocorrelation [11]. The closer AUC is to 1, the more predictive is the model. Random distribution has an AUC of 0.5 . Overall value of AUC can be considered in evaluating the final model. AUC values of $0.5-0.7$ indicate low accuracy, 0.7-0.9 useful applications and $>0.9$ high accuracy [33].

\section{Assessment of variable contribution}

The Jackknife procedure was performed on climate variables to determine the major contributors to the prediction model. The model evaluation was completed by an assessment of the contribution of each variable used in the model based on Jackknife test. However, more detailed evaluation can be carried out during construction of the model by analyzing AUC obtained in different Jackknife test scenario. Then, AUC values obtained from a single variable or with the global models (from which a variable had been removed purposively) can be compared. The main goal in such situation is to identify which variable, when added or removed from the model, mainly modify the AUC value. In this study, the jackknife method was used to analyze the effects of environmental variables on model results in order to select dominant factors. Specifically, the process involves 3 independent steps:

1. Calculating the training gain for the model with only one variable. Higher training gain indicates that the 
variable has high prediction power and contributes greatly to species distribution;

2. Calculating the training gain for the model without a specific variable and analyzing the correlation between the removed variable and the omission error. If the removal of an environmental variable leads to a significant increase in the omission error, it indicates that the variable has a significant effect on the model's prediction;

3. Calculating the training gain for the model with all variables.

\begin{abstract}
Abbreviations
AUC: Area under the curve; ROC: Receiver operating characteristic; MaxEnt: Maximum entropy; SDM: Species distribution model; HCPC: Hierarchical clustering on principle components; PCA: Principal component analysis; CLIMEX: Climate and population modeling software; DRC: Democratic Republic of Congo.
\end{abstract}

\section{Acknowledgements}

The authors acknowledge the help of Kazamwali Muzee Léon. The Université Evangélique en Afrique (UEA) is dully acknowledged through Professor Gustave Mushagalusa and Professor Katcho Karume, for manifold support to this work which had graciously been founded by the University project on human resource development for improvement of research and teaching quality funded by Pain pour le Monde (Project A-COD-2018-0383).

\section{Authors' contributions}

FF and EBB planned and supervised the project. MCC and YM performed the experiments, analyzed the data, and contributed reagents/materials/analysis tools. NG, GBC, DMB and ANB analyzed the data and performed simulations. All authors contributed to the writing and revision of the final manuscript. All authors read and approved the final manuscript.

\section{Funding}

This study was made possible with the financial support of Pain pour le Monde and Académie de recherche et d'enseignement supérieur (ARES) The funding body did not play any additional role in the design, collection, analysis, data interpretation, and/or writing of this study.

\section{Availability of data and materials}

The datasets used and/or analyzed during the current study are available from the corresponding author on reasonable request.

\section{Ethics approval and consent to participate}

The research reported here was carried out in strict accordance with ethical guidelines and regulations in the standard operating procedures of the Université Evangélique en Afrique (UEA/Bukavu-DR Congo). Collection of fall armyworm occurrence data was approved with the approval reference number UEA/FACAGRO/KK/051/2018 and permitted by the Provincial Inspection of Agriculture, Livestock and Fisheries (Reference number: 18.0/0056/IPAPEL/ SK/2018).

\section{Consent for publication}

Not applicable.

\section{Competing interests}

The authors declare that they have no competing interests.

\section{Author details}

1 Unit of Crop Sciences, Faculty of Agriculture and Environmental Sciences, Université Evangélique en Afrique, South Kivu, P.O Box: 3323, Bukavu, Democratic Republic of Congo. ${ }^{2}$ Functional and Evolutionary Entomology,
Gembloux Agro-Bio Tech, Liege University, Passage des Déportés 2, 5030 Gembloux, Belgium. ${ }^{3}$ Unit of Applied Biostatistics, Faculty of Agriculture and Environmental Sciences, Université Evangélique en Afrique, South Kivu, P.O Box: 3323, Bukavu, Democratic Republic of Congo. ${ }^{4}$ Unit of Geographic Information System, Faculty of Agriculture and Environmental Sciences, Université Evangélique en Afrique, South Kivu, P.O Box: 3323, Bukavu, Democratic Republic of Congo. ${ }^{5}$ Faculty of Agriculture, Université Catholique de Bukavu, South Kivu, P.O Box: 285, Bukavu, Democratic Republic of Congo.

Received: 15 June 2020 Accepted: 19 November 2020

Published online: 30 November 2020

\section{References}

1. Abrahams P, Beale T, Cock M, Corniani N, Day R, Godwin J, et al. Impacts and control options in Africa: preliminary evidence. Note. 2017;18:99.

2. Austin MP, Belbin L, Meyers JA, Doherty MD, Luoto M. Evaluation of statistical models used for predicting plant species distributions: role of artificial data and theory. Ecol Model. 2006;199:197-216.

3. Bale JS, Masters GJ, Hodkinson ID, Awmack C, Bezemer TM, Brown VK, et al. Herbivory in global climate change research: direct effects of rising temperature on insect herbivores. Glob Ch Biol. 2002;8:1-16.

4. Barve N, Barve V, Jiménez-Valverde A, Lira-Noriega A, Maher SP, Peterson $A T$, et al. The crucial role of the accessible area in ecological niche modeling and species distribution modeling. Ecol Model. 2011;222:1810-9.

5. Baudron F, Zaman-Allah MA, Chaipa I, Chari N, Chinwada P. Understanding the factors influencing fall armyworm (Spodoptera frugiperda J.E. Smith) damage in African smallholder maize fields and quantifying its impact on yield. A case study in Eastern Zimbabwe. Crop Prot. 2019;120:141-50

6. Biber-Freudenberger L, Ziemacki J, Tonnang HEZ, Borgemeister C. Future risks of pest species under changing climatic conditions. PLoS ONE. 2016;11:e0153237.

7. Bradie J, Leung B. A quantitative synthesis of the importance of variables used in MaxEnt species distribution models. J Biog. 2017;44:1344-61.

8. Busato GR, Grützmacher AD, Garcia MS, Giolo FP, Zotti MJ, Stefanello Júnior GJ. Biologia comparada de populações de Spodoptera frugiperda (J.E. Smith) (Lepidoptera: Noctuidae) em folhas de milho e arroz. Neotrop Entomol. 2005;34:743-50.

9. CABI. Invasive Species Compendium Datasheets-Spodoptera frugiperda (fall armyworm). 2020. https://www.cabi.org/isc/datasheet/29810. Accessed 21 Jan 2020.

10. Cokola CM. Monitoring, caractérisation moléculaire et lutte biologique contre Spodoptera frugiperda (Lepidoptera: Noctuidae). Travail de fin d'études, Gembloux Agro-Bio Tech, Université de Liège. 2019. http:// matheo.uliege.be/handle/2268.2/8077.

11. Cumming GS. Comparing climate and vegetation as limiting factors for species ranges of African ticks. Ecol. 2002;83:255-68.

12. Day R, Abrahams P, Bateman M, Beale T, Clottey V, Cock M, et al. Fall armyworm: impacts and implications for Africa. Outlooks Pest Manag. 2017;28:196-201.

13. Du Plessis H, Van den Berg J, Ota N, Kriticos DJ. Spodoptera frugiperda. CSIRO - InSTePP Pest Geog. 2018;1-7.

14. Early R, González-Moreno P, Murphy ST, Day R. Forecasting the global extent of invasion of the cereal pest Spodoptera frugiperda, the fall armyworm. NeoBiota. 2018;40:25-50.

15. Nagoshi RN, Meagher RL, Hay-Roe M. Inferring the annual migration patterns of fall armyworm (Lepidoptera: Noctuidae) in the United States from mitochondrial haplotypes: Fall armyworm migration. Ecol Evol. 2012;2:1458-67.

16. EPPO. PM 7/124 (1) Spodoptera littoralis, Spodoptera litura, Spodoptera frugiperda, Spodoptera eridania. EPPO Bull. 2015;45:410-444.

17. Elith J, Leathwick JR. Species distribution models: ecological explanation and prediction across space and time. Annu Rev Ecol Evol Syst. 2009;40:677-97.

18. FAO. Integrated management of the Fall Armyworm on maize: a guide for farmer field schools in Africa. 2018.

19. Fourcade Y, Engler JO, Rödder D, Secondi J. Mapping species distributions with MAXENT using a geographically biased sample of presence data: a 
performance assessment of methods for correcting sampling bias. PLoS ONE. 2014;9:e97122.

20. Goergen G, Kumar PL, Sankung SB, Togola A, Tamò M. First Report of Outbreaks of the Fall Armyworm Spodoptera frugiperda (J E Smith) (Lepidoptera, Noctuidae), a New Alien Invasive Pest in West and Central Africa. PLOS ONE. 2016;11:e0165632.

21. Guisan A, Thuiller W. Predicting species distribution: offering more than simple habitat models. Ecol Letters. 2005;8:993-1009.

22. Du Plessis H, Schlemmer M-L, Van den Berg J. The effect of temperature on the development of Spodoptera frugiperda (Lepidoptera: Noctuidae). Insects. 2020;11:228.

23. Hijmans RJ, Cameron SE, Parra JL, Jones PG, Jarvis A. Very high resolution interpolated climate surfaces for global land areas. Int J Climatol. 2005;25:1965-78.

24. Hill MP, Hoffmann AA, McColl SA, Umina PA. Distribution of cryptic blue oat mite species in Australia: current and future climate conditions. Agr Forest Entomol. 2012;14:127-37.

25. Hogg DB, Pitre HN, Anderson RE. Assessment of early-season phenology of the fall armyworm (Lepidoptera: Noctuidae) in Mississippi 1. Environ Entomol. 1982:11:705-10.

26. Sharanabasappa S, Kalleshwaraswamy CM, Maruthi MS, Pavithra HB. Biology of invasive fall army worm Spodoptera frugiperda (J.E. Smith) (Lepidoptera: Noctuidae) on maize. Indian J Entomol. 2018;80:540.

27. Hruska AJ, Gould F. Fall Armyworm (Lepidoptera: Noctuidae) and Diatraea lineolata (Lepidoptera: Pyralidae): Impact of Larval Population Level and Temporal Occurrence on Maize Yield in Nicaragua. J Econ Entomol. 1997;90:611-22.

28. Jiménez-Valverde A, Lobo JM, Hortal J. Not as good as they seem: the importance of concepts in species distribution modelling. Divers Distrib. 2008; 14:885-90

29. Juárez ML, Schöfl G, Vera MT, Vilardi JC, Murúa MG, Willink E, et al. Population structure of Spodoptera frugiperda maize and rice host forms in South America: are they host strains? Entom Exp Appl. 2014;152:182-99.

30. Labatte JM. Modelling the larval development of Spodoptera frugiperda (J. E. Smith), (Lep., Noctuidae) on corn. J Appl Entomol. 1994:118:172-8.

31. Lê S, Josse J, Husson F. FactoMineR : An R package for multivariate analysis. J Stat Soft. 2008. https://doi.org/10.18637/jss.v025.i01.

32. Liu T, Wang J, Hu X, Feng J. Land-use change drives present and future distributions of Fall armyworm, Spodoptera frugiperda (JE Smith) (Lepidoptera: Noctuidae). Sci Tot Environ. 2020;706:135872.

33. Manel S, Williams HC, Ormerod SJ. Evaluating presence-absence models in ecology: the need to account for prevalence: Presence-absence modelling. J Appl Ecol. 2002;38:921-31.

34. Montezano DG, Specht A, Sosa-Gómez DR, Roque-Specht VF, Sousa-Silva JC, Paula-Moraes SV, et al. Host Plants of Spodoptera frugiperda (Lepidoptera: Noctuidae) in the Americas. Afr Entomol. 2018;26:286-300.

35. Nagoshi RN. The fall armyworm triose phosphate isomerase (Tpi) gene as a marker of strain identity and interstrain mating. Ann Entomol Soc Am. 2010;103:283-92.

36. Nagoshi RN, Goergen G, Plessis HD, van den Berg J, Meagher R. Genetic comparisons of fall armyworm populations from 11 countries spanning sub-Saharan Africa provide insights into strain composition and migratory behaviors. Sci Rep. 2019. https://doi.org/10.1038/s41598-019-44744 $-9$.

37. Nagoshi RN, Meagher RL. Seasonal distribution of fall armyworm (Lepidoptera: Noctuidae) host strains in agricultural and turf grass habitats. Environ Entomol. 2004;33:881-9.

38. Pashley DP, Martin JA. Reproductive Incompatibility between host strains of the fall armyworm (Lepidoptera: Noctuidae). Ann Entomol Soc Am. 1987;80:731-3

39. Patterson DT, Westbrook JK, Joyce RJV, Lingren PD, Rogasik J. Weeds, insects, and diseases. Clim Ch. 1999:43:711-27.
40. Pearce J, Ferrier S, Scotts D. An evaluation of the predictive performance of distributional models for flora and fauna in north-east New South Wales. J Env Manag. 2001;62:171-84.

41. Peterson AT. Uses and requirements of ecological niche models and related distributional models. Biodiv Inform. 2006. https://doi. org/10.17161/bi.v3i0.29.

42. Peterson AT, Papes M, Carroll DS, Leirs H, Johnson KM. Mammal taxa constituting potential coevolved reservoirs of filoviruses. J Mamm. 2007:88:1544-54

43. Phillips SJ, Anderson RP, Dudík M, Schapire RE, Blair ME. Opening the black box: an open-source release of Maxent. Ecography. 2017;40:887-93.

44. Phillips SJ, Anderson RP, Schapire RE. Maximum entropy modeling of species geographic distributions. Ecol Model. 2006;190:231-59.

45. Phillips SJ, Dudík M, Schapire RE. A maximum entropy approach to species distribution modeling. In: Twenty-first international conference on Machine learning - ICML '04. Banff, Alberta, Canada: ACM Press; 2004. p. 83. doi:https://doi.org/10.1145/1015330.1015412.

46. Prasanna BM, Huesing JE, Eddy R, Peschke VM (eds). Fall Armyworm in Africa: A Guide for Integrated Pest Management, First Edition. Mexico, CDMX: CIMMYT. 2018.

47. Prowell DP, MCMichael M, Silvain J-F. Multilocus genetic analysis of host use, introgression, and speciation in host strains of fall armyworm (Lepidoptera: Noctuidae). Ann Entomol Soc Am. 2004;97:1034-44.

48. R Development Core Team. R statistical software (R Foundation for statistical computing: Vienna, Austria). 2018.

49. Ramirez-Cabral NYZ, Kumar L, Shabani F. Future climate scenarios project a decrease in the risk of fall armyworm outbreaks. J Agr Sci. 2017;155:1219-38.

50. Schöfl G, Heckel DG, Groot AT. Time-shifted reproductive behaviours among fall armyworm (Noctuidae: Spodoptera frugiperda) host strains: evidence for differing modes of inheritance. J Evol Biol. 2009:22:1447-59.

51. Sharanabasappa D, Kalleshwaraswamy CM, Asokan R, MahadevaSwamy HM, Maruthi MS, Pavithra HB, Hegde K, Navi S, Prabhu ST, Goergen G. First report of the fall armyworm, Spodoptera frugiperda (J E Smith) (Lepidoptera: Noctuidae), an alien invasive pest on maize in India. Pest Manag Hort Ecosyst. 2018;24(1):23-9.

52. Shylesha AN, Jalali SK, Gupta A, Varshney R, Venkatesan T, Shetty P, Ojha R, Ganiger PC, Navik O, Subaharan K, Bakthavatsalam N, Ballal CR. Studies on new invasive pest Spodoptera frugiperda (JE Smith) (Lepidoptera: Noctuidae) and its natural enemies. J Biol Control. 2018;32:145-51.

53. Soria-Auza RW, Kessler M, Bach K, Barajas-Barbosa PM, Lehnert M, Herzog SK, et al. Impact of the quality of climate models for modelling species occurrences in countries with poor climatic documentation: a case study from Bolivia. Ecol Model. 2010;221:1221-9.

54. Sparks AN. A Review of the Biology of the Fall Armyworm. Fla Entomol. 1979:62:82.

55. Wang R, Jiang C, Guo X, Chen D, You C, Zhang Y, et al. Potential distribution of Spodoptera frugiperda (J.E. Smith) in China and the major factors influencing distribution. Glob Ecol Conserv. 2020;21:e00865.

56. Westbrook J, Fleischer S, Jairam S, Meagher R, Nagoshi R. Multigenerational migration of fall armyworm, a pest insect. Ecosphere. 2019. https:// doi.org/10.1002/ecs2.2919.

57. Westbrook JK, Nagoshi RN, Meagher RL, Fleischer SJ, Jairam S. Modeling seasonal migration of fall armyworm moths. Int J Biomet. 2016;60:255-67.

58. Elith J, Kearney M, Phillips S. The art of modelling range-shifting species. Meth Ecol Evol. 2010;1:330-42.

\section{Publisher's Note}

Springer Nature remains neutral with regard to jurisdictional claims in published maps and institutional affiliations. 